\title{
STRATEGI REGULASI EMOSI NARAPIDANA ANAK DI LEMBAGA PEMBINAAN KHUSUS ANAK (LPKA) KLAS II TANJUNG PATI PAYAKUMBUH
}

\author{
Rina Mariana ${ }^{1)}$, Maulany Putry Sagita ${ }^{2)}$ \\ Fakultas Psikologi, Universitas Putra Indonesia "YPTK" Padang. \\ E-mail: rinadeded@gmail.com, maulany.putry09@gmail.com
}

\begin{abstract}
This study aims to find out how the emotional regulation strategies of child prisoners in Class II $\mathrm{Tj}$ LPKA. Pati..Using the one used is Quantitative Descriptive method. Emotional regulation on child inmates was revealed using a questionnaire about emotion regulation strategies. The results of research derived from questionnaires and interviews conducted showed that out of 32 child inmates, as many as 32 child prisoners usedemotionregulation strategies cognitivereappraisal in dealing with problems in the LPKA environment. In addition, as many as 7 adolescents have a tendency to useemotionstrategies cognitivereappraisal and expressive suppressionin dealing with problems in the LPKA environment. Based on the results of the study it was found that $9.37 \%$ of child prisoners had poor emotion regulation strategies, and $71.87 \%$ of child inmates have a fairly good emotion regulation strategy and $18.75 \%$ have a good emotion regulation strategy.
\end{abstract}

Keywords: Emotion Regulation Strategy, Child Prisoners

\begin{abstract}
Abstrak
Penelitian ini bertujuan untuk mengetahui bagaimana strategi regulasi emosi narapidana anak di LPKA Klas II Tj. Pati..Menggunakan yang digunakan adalah metode Deskriptif Kuantitatif. Regulasi emosi pada narapidana anak diungkap menggunakan kuesioner tentang strategi regulasi emosi. Hasil penelitian yang berasal dari kuesioner dan wawancara yang dilakukan menunjukkan bahwa dari 32 narapidana anak, sebanyak32narapidana anakmenggunakan strategi regulasi emosi cognitive reappraisal dalam menghadapi permasalahan-permasalahan di lingkungan LPKA. Selain itu, sebanyak 7 remaja yang memiliki kecenderungan menggunakan strategi regulasi emosi cognitive reappraisal dan expressive suppressiondalam menghadapi permasalah-permasalahan di lingkungan LPKA.Berdasarkan hasil penelitian ditemukan bahwa 9,37\% narapidana anak memiliki strategi regulasi emosi yang kurang baik, dan $71,87 \%$ narapidana anak memiliki strategi regulasi emosi yang cukup baik dan $18,75 \%$ memiliki strategi regulasi emosi yang baik.
\end{abstract}

Kata Kunci:Strategi Regulasi Emosi, Narapidana Anak

\section{Pendahuluan}

Lembaga pemasyarakatan (Lapas) atau dalam bahasa masyarakat awam dikenal dengan penjara, merupakan tempat atau kediaman bagi orang-orang yang bermasalah dengan hukum.Lapas dibagi menjadi Lapas untuk pria dan Lapas untuk wanita dan dalam pelaksanaannya masing-masing juga akan dipisahkan antara Lapas untuk orang dewasa dan Lapas untuk anak-anak. Untuk anak-anak Lapas diganti nama menjadi Lembaga Pembinaan Khusus Anak (LPKA). LPKA dihuni oleh narapidana anak yang kemudian disebut anak didik, 
berusia 8-18 tahun. Untuk anak didik yang berusia 18 tahun keatas akan ditempatkan di Lapas dewasa. Baik Lapas anak dan Lapas dewasa memiliki tujuan yang sama yaitu menjadi sarana untuk memperbaiki diri bagi para penghuninya sehingga bisa diterima kembali dilingkungan masyarakat. ${ }^{[8]}$

Gussak menyatakan menjadi anak didik adalah stresor kehidupan yang berat bagi pelakunya. Perasaan sedih pada anak didik setelah menerima hukuman serta berbagai hal lainnya seperti rasa bersalah, hilangnya kebebasan, perasaan malu, sangsi ekonomi, dan sosial serta kehidupan dalam lembaga pembinaan khusus anak yang penuh dengan tekanan psikologis dapat memperburuk dan mengintensifkan stresor sebelumnya. Keadaan tersebut bukan saja mempengaruhi penyesuaian fisik tetapi juga psikologis individu. ${ }^{[6]}$

Berdasarkan hasil wawancara yang dilakukan pada tanggal 6 Oktober 2017 dengan lima orang anak didik di Lembaga Pembinaan Khusus Anak (LPKA) Klas II Tj. Pati dimana diperoleh keterangan bahwa salah satu permasalahan yang cukup penting pada anak didik adalah masalah emosional. Dimana empat diantara lima anak didik mengalami perasaan sedih, cemas, hampa, bosan dan putus asa. Hal ini disebabkan karena mereka merasa stres, tertekan dan sulit dalam penyesuaian diri dengan lingkungan yang baru. Tekanan yang dirasakan anak didik terutama disebabkan karena ruang gerak yang dibatasi seperti mereka tidak boleh menggunakan alat komunikasi seperti handphone, sehingga mereka sering merasa sedih merindukan keluarga mereka. Anak didik juga mengakui bahwa mereka mengalami sulit tidur dan menanggis dimalam hari ketika merindukan keluarga Selain perasaan tertekan, anak didik juga merasakan rasa cemas karena dirinya merasa khawatir akan adanya bahaya yang mengancam dirinya setelah bebas nanti seperti dikucilkan dan bagaimana stigma atau pandangan masyarakat akan kehadirannya. Kemarahan juga sering dirasakan oleh anak didik, penyebabnya adalah karena mereka tidak bisa atau belum menerima vonis hukuman dari pengadilan yang dipandang terlalu berat dan juga kemarahan akibat perselisihan yang terjadi antar anak didik, yang disebabkan penindasan yang dilakukan oleh anak didik lama terhadap anak didik yang baru masuk. Seperti pembagian tugas dalam merawat dan menjaga kebersihan kamar yang tidak adil.Bosan juga dirasakan anak didik karena mereka diizinkan keluar dari kamar sebentar yaitu ketika pagi hari untuk mandi, sarapan dan melakukan kegiatan keterampilan juga untuk sholat zhuhur berjamaan setelah itu mereka berada didalam kamar sampai besok pagi lagi.Perasaan bosan tersebut membuat anak didik sering merasa sakit kepala, gelisah, perasaan yang tidak berdaya serta mudah marah atau tersinggung yang menimbulkan perkelahian sesama anak didik.Berbeda dengan satu orang anak didik yang berinisial $B$ yang tidak merasa tertekan ataupun jenuh selama berada di LPKA karena B bisa berbagi cerita dengan anak didik lainnya. B juga mengungkapkan bahwa semuanya sudah terjadi dan ia menerima konsekuensi dari kesalahan yang dia kerjakan.

Penelitian ini dilakukan untuk mengetahui bagaimana strategi regulasi emosi narapidana anak di LPKA Klas II Tj. Pati.

\section{Regulasi Emosi}

Regulasi emosi menurut Gross ${ }^{[8]}$ adalah proses pengenalan, pemeliharaan, dan pengaturan emosi positif maupun negatif, baik yang tampak maupun yang tersembunyi, baik disadari maupun tidak disadari.Menurut Gottman dan $\mathrm{Katz}^{[1]}$ regulasi emosi merujuk pada kemampuan untuk menghalangi perilaku tidak tepat akibat kuatnya intensitas emosi positif atau negatif yang dirasakan, dapat menenangkan diri dari pengaruh psikologis yang timbul akibat intensitas yang kuat dari emosi, dapat memusatkan perhatian kembali dan mengorganisir diri sendiri untuk mengatur perilaku yang tepat untuk mencapai suatu tujuan.Reivich \&Shatte ${ }^{[1]}$ regulasi emosi adalah kemampuan untuk tetap tenang dibawah tekanan. Individu yang memiliki kemampuan regulasi emosi dapat mengendalikan dirinya apabila sedang kesal dan dapat mengatasi rasa cemas, sedih, atau marah sehingga mempercepat dalam pemecahan suatu masalah. 


\section{Aspek-Aspek Strategi Regulasi Emosi}

Menurut Gross dan John (2003) $)^{[4]}$, strategi regulasi emosi dibagi menjadi dua :

a. Cognitive Reappraisal, yaitu bentuk perubahan kognitif yang melibatkan menafsirkan situasi yang berpotensi memunculkan emosi dengan cara mengubah dampak emosional.

b. Expressive Suppression, yaitu suatu bentuk modulasi respon yang melibatkan hambatan perilaku ekspresi emosi.

\section{Narapidana Anak}

Narapidana anak menurut Undang-Undang nomor 11 tahun 2012 tentang system peradilan pidana anak pasal 1 ayat 3 anak adalah yang telah berumur 12 (dua belas) tahun, tetapi belum berumur 18 (delapan belas) tahun yang diduga melakukan tindak pidana. UU No. 3 tahun 1997 pasal 4 ayat 1 dan 2 menyatakan bahwa; (1) batas umur anak nakal yang dapat diajukan ke sidang anak adalah sekurang-kurangnya 8 (delapan) tahun tetapi belum mencapai umur 18 (delapan belas) tahun dan belum pernah kawin, (2) dalam hal anak melakukan tindak pidana pada batas umur sebagaimana dimaksud dalam ayat (1) dan diajukan ke sidang pengadilan setelah anak bersangkutan melampaui batas umur tersebut tetapi belum mencapai umur 21 (dua puluh satu) tahun, tetap diajukan ke sidang anak.

\section{Metode Penelitian}

Menggunakan metode Deskriptif Kuantitatif. Penelitian ini termasuk jenis penelitian deskriptif dengan pendekatan kuantitatif. Ali ${ }^{[7]}$, menjelaskan bahwa metode penelitian deskriptif digunakan untuk memecahkan sekaligus menjawab permasalahan yang terjadi di masa sekarang. Dilakukan dengan menempuh langkah-langkah pengumpulan klasifikasi dan analisis atau pengolahan data, membuat kesimpulan dan laporan dengan tujuan utama untuk menggambarkan tentang suatu keadaan secara objektif dalam suatu deskripsi. Sedangkan yang dimaksud dengan pendekatan kuantitatif adalah pendekatan yang digunakan dalam penelitian dengan cara mengukur indikator-indikator variabel penelitian sehingga diperoleh gambaran diantara variabel-variabel tersebut.

Tujuan dari pendekatan kuantitatif menurut Surakhmad ${ }^{[7]}$ adalah untuk mengukur dimensi yang hendak diteliti. Penggunaan metode deskriptif kuantitatif ini diselaraskan dengan variabel penelitian yang memusatkan pada masalah-masalah aktual dan fenomena yang sedang terjadi pada saat sekarang dengan bentuk hasil penelitian dengan angka-angka yang penuh makna. Sebagaimana dikemukakan oleh Sudjana ${ }^{[7]}$, metode penelitian deskriptif dengan pendekatan kuantitatif digunakan apabila bertujuan untuk mendeskripsikan atau menjelaskan peristiwa dalam suatu kejadian yang terjadi pada saat sekarang yang berbentuk angka-angka yang bermakna.

Adapun tujuan penelitian deskriptif dengan pendekatan kuantitatif ini adalah untuk menjelaskan suatu situasi yang hendak diteliti dengan dukungan studi kepustakaan sehingga lebih memperkuat analisa peneliti dalam membuat kesimpulan dimana hasil penelitian diperoleh dari hasil perhitungan indikator-indikator variabel penelitian kemudian di paparkan secara tertulis oleh penulis.

\section{Identifikasi Variabel Penelitian}

Sugiyono ${ }^{[9]}$ menjelaskan bahwa variable penelitian adalah suatu atribut atau sifat atau nilai dari orang, obyek, atau kegiatan yang mempunyai variasi tertentu yang ditetapkan oleh peneliti untuk dipelajari dan kemudian ditarik kesimpulannya. Dalam penelitian ini hanya terdapat satu variable (variable tunggal) yaitu regulasi emosi.

\section{Definisi Operasional Variabel Penelitian}


Definisi operasional adalah definisi yang didasarkan atas sifat-sifat hal yang didefenisikan yang dapat diamati atau diobservasi . [10]

Regulasi emosi merupakan kemampuan seseorang agar dapat mengatur, mengelola dan mengekspresikan emosinya dengan tepat agar dapat berperilaku adaptif.

Regulasi emosi dalam penelitian ini diukur dengan menggunakan skala strategi regulasi emosi berdasarkan aspek strategi regulasi emosi yaitu cognitive reappraisal dan expressive suppression menurut Gross dan John . ${ }^{[4]}$

\section{Populasi dan Sampel}

\section{Populasi}

Populasi adalah wilayah generalisasi yang terdiri dari obyek atau subyek yang mempunyai karakteristik tertentu yang ditetapkan oleh peneliti untuk dipelajari dan kemudian ditarik kesimpulannya. ${ }^{[9]}$

Populasi dalam penelitian ini adalah seluruh Anak Didik di Lembaga Pembinaan Khusus Anak (LPKA) Klas II Tj. Pati yang berjumlah 32 orang.

\section{Sampel}

Sampel adalah sebagian dari populasi itu. Sampel harus memiliki ciri-ciri yang dimiliki oleh populasinya. ${ }^{[9]}$ Sampel adalah bagian dari jumlah dan karakteristik yang dimiliki oleh populasi tersebut. Sampel yang diambil dari populasi harus betul-betul representatif (mewakili).Teknik pengambilan sampel pada penelitian ini adalah sampling jenuh, dimana semua anggota populasi dijadikan sebagai sampel. Teknik sampel jenuh adalah teknik penentuan sampel bila semua anggota populasi digunakan sebagai sampel. ${ }^{[8]}$ Sampel dalam penelitian ini yaitu seluruh narapidana anak penghuni LPKA Tj. Pati yang berjumlah 32 orang.

\section{Metode dan Alat Pengumpulan Data}

\section{Alat ukur penelitian}

Alat ukur yang digunakan dalam pengumpulan data adalah wawancara mengenai strategi regulasi emosi, angket strategi regulasi emosi dan dokumentasi.Menurut Sugiyono ${ }^{[8]}$, Angket merupakan teknik pengumpulan data yang dilakukan dengan cara memberi seperangkat pertanyaan atau pernyataan tertulis kepada responden untuk dijawabnya. Pada penelitian ini angket disusun menggunakan pengukuran dari Guttman. Pengukuran dalam tipe ini akan didapat jawaban yang tegas yaitu: Ya-Tidak, Benar-Salah, dan lain-lain. ${ }^{[9]}$ Strategi Regulasi Emosi diukur dengan menggunakan teori dari Grossyang mengatakan bahwa ada 3 dimensi dari strategi regulasi emosi yaitu dimensi cognitive reappraisal dan expressive suppression. ${ }^{[4]}$

Gorden ${ }^{[10]}$ mendefinisikan wawancara merupakan percakapan antara dua orang yang salah satunya bertujuan untuk menggali dan mendapatkan informasi untuk suatu tujuan tertentu. Peneliti menggunakan teknik wawancara semi-terstruktur. Beberapa ciri wawancara semi-terstruktur dijelaskan sebagai berikut ${ }^{[5]}$ :

1. Pertanyaan terbuka, namun ada batasan tema dan alur pembicaraan.

2. Kecepatan wawancara dapat diprediksi.

3. Fleksibel, tetapi terkontrol.

4. Ada pedoman wawancara yang dijadikan patokan dalam alur, urutan, dan penggunaan kata.

5. Tujuan wawancara adalah untuk memahami suatu fenomena.

Dokumentasi digunakan untuk mendapatkan informasi atau data yang berkaitan dengan penelitian. Dalam penelitian ini dokumentasi diganakan untuk melengkapi penelitian mengenai regulasi emosipada narapidana anak di LPKA Klas II Tj. Pati 


\section{Uji coba alat ukur}

\section{a. Uji Validitas}

Valid berarti instrumen tersebut dapat digunakan untuk mengukur apa yang seharusnya diukur. Peneliti melakukan pengujian konstruksi mengenai aspek yang diukur kepada ahli (judgement experts. Pengujian validitas dengan menggunakan expert judgement dilaksanakan dengan penelaahan terhadap kisi-kisi instrumen apakah telah sesuai dengan tujuan penelitian,setelah itu dilakukan penelaahan terhadap kesesuaian alat ukur penelitian serta penelaahan terhadap item-item pertanyaan yang diajukan terhadap responden.

Setelah didapatkan data uji instrumen, penyusun melakukan tabulasi pada tabel Guttman dengan menyusun item menurut ukuran skor jawaban "Ya" tertinggi sampai dengan yang paling rendah, hasil tabulasi Guttman terlampir. Karena instrumen dalam penelitian ini menggunakan kuesioner dengan skala Guttman maka untuk memperoleh tingkat validitas instrumen kuesioner, penyusun menggunakan koefisien Reprodusibilitas dan koefisien Skalabilitas.Uji validitas angket strategi regulasi emosi dilakukan dengan manual menggunakan rumus Koefisien Reprodusibilitas ( $\mathrm{Kr}$ ) dan Koefisien Skalabilitas (Ks).Hasil uji coba terpakai, instrumen pengukur strategi regulasi emosi yang dikembangkan dalam penelitian ini menunjukkan bahwa nilai dari hasil perhitungan $\mathrm{Kr}$ sebesar 0,71 maka koefisien reprodusibilitas untuk hasil uji instrumen ini dianggap cukup baik. Skala yang memiliki nilai $\mathrm{Kr}>0,90$ dianggap baik. Dalam perhitungan Koefisien Skalabilitas menghasilkan 0,40 maka, hasil koefisien skalabilitas ini di katakan cukup baik. Dalam perhitungan koefisien skalabilitas, jika nilai Ks > 0,60 maka dianggap baik untuk digunakan dalam penelitian.

\section{b. Uji Reliabilitas}

Reliabilitas diterjemahkan dari kata reliability. Reliabilitas berkenaan dengan taraf keterpercayaan atau taraf konsistensi hasil ukur (Azwar, 2016). ${ }^{[2]}$ Pengujian reliabilitas dalam uji instrumen ini adalah dengan internal consistency, yakni dilakukan dengan cara menguji cobakan instrumen sekali saja, kemudian setelah data diperoleh lalu dianalisis dengan teknik tertentu. Uji reliabilitas dilakukan dengan menggunakan KR 20 (Kuder Richardson).Uji reliabilitas angket strategi regulasi emosi menggunakan teknik KR 20diperoleh hasil uji reliabilitas sebesar 0,10 menunjukkan bahwa reliabel untuk digunakan dalam penelitian.

\section{HASIL DAN PEMBAHASAN}

\section{Hasil Penelitian}

Hasil analisis Kuantitatif data strategi regulasi emosi narapidana anak di LPKA Tj. Pati Payakumbuh :

Tabel 1

Deskripsi Usia Subjek Narapidana Anak di LPKA Tj. Pati

\begin{tabular}{|c|c|c|c|c|}
\hline No & Usia & Tally & Jumlah & \% \\
\hline 1 & 14 & II & 2 & $6,25 \%$ \\
\hline 2 & 15 & II & 2 & $6,25 \%$ \\
\hline 3 & 16 & ЖI III & 8 & $25 \%$ \\
\hline 4 & 17 & ЖI II & 7 & $21,88 \%$ \\
\hline 5 & 18 & ЖII Ж I I & 11 & $34,38 \%$ \\
\hline
\end{tabular}




\begin{tabular}{|c|c|c|c|c|}
6 & 19 & $\mathrm{I}$ & 1 & $3,13 \%$ \\
\hline Jumlah & 32 & 32 & $100 \%$ \\
\hline
\end{tabular}

Berdasarkan tabel 1 di atas, diperoleh diperoleh hasil deskripsi usia subjek penelitian yang menunjukkan usia 14 tahun berjumlah 2orang $(6,25 \%)$, usia 15 tahun berjumlah 2 orang $(6,25 \%)$, usia 16 tahun berjumlah 8 orang( $25 \%)$, usia 17 tahun berjumlah 7 orang $(21,88 \%)$, usia 18 tahun berjumlah 11 orang $(34,38 \%)$,usia 19 tahun berjumlah 1 orang $(3,13 \%)$.

Tabel 2

B

Deskripsi Jenis KelaminSubjek Narapidana Anak

\begin{tabular}{|c|c|c|c|c|}
\hline No & Jenis kelamin & Tally & Jumlah & $\%$ \\
\hline e 1 & Laki-laki & योग सूN & 32 & $100 \%$ \\
\hline 2 & Perempuan & - & 0 & $0 \%$ \\
\hline & Jumlah & 32 & 32 & $100 \%$ \\
\hline
\end{tabular}

Berdasarkan tabel 2 di atas dapat diperoleh hasil deskripsi jenis kelamin subjek penelitian yang menunjukkan berjenis kelamin laki-laki berjumlah 32 orang (100\%).

Tabel 3

Deskripsi Agama Subjek Narapidana Anak

\begin{tabular}{|c|c|c|c|c|}
\hline Blo & Agama Subjek & Tally & Jumlah & $\%$ \\
\hline 1 & Islam & 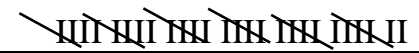 & 32 & $100 \%$ \\
\hline 2 & Non Islam & - & 0 & $0 \%$ \\
\hline \multicolumn{2}{|r|}{ Jumlah } & 32 & 32 & $100 \%$ \\
\hline
\end{tabular}

Berdasarkan tabel 3 di atas dapat diperoleh hasil deskripsi agama subjek penelitian yang menunjukkan agama islam berjumlah 32 orang (100\%).

Tabel 4

Deskripsi Pendidikan SubjekNarapidana Anak

\begin{tabular}{|c|c|c|c|c|}
\hline \\
\hline No & Pendidikan Terakhir & Tally & Jumlah & $\%$ \\
\hline 1 & $\mathrm{SD} /$ sederajat & ЖLI III & 8 & $25 \%$ \\
\hline 2 & SMP/sederajat & Ж世 IIII & 10 & $31,25 \%$ \\
\hline 3 & SMA/sederajat & W世 INLIIII & 14 & $43,75 \%$ \\
\hline & Jumlah & 32 & 32 & $100 \%$ \\
\hline
\end{tabular}

Berdasarkan tabel 4 di atas dapat diperoleh hasil deskripsi pendidikan subjek penelitian yang menunjukkan pendidikan SD berjumlah 8 orang (25\%), SMP berjumlah 10 orang $(31,25 \%)$, SMA berjumlah 14 orang $(43,75 \%)$.

Tabel 5

Deskripsi Kasus SubjekNarapidana Anak 


\begin{tabular}{|c|c|c|c|c|}
\hline No & Kasus & Tally & Jumlah & $\%$ \\
\hline 1 & Asusila & IN IINIIN & 15 & $46,8 \%$ \\
\hline 2 & Pencurian & TWIIII & 9 & $28,3 \%$ \\
\hline 3 & Narkotika & TH I & 6 & $18,75 \%$ \\
\hline 4 & Laku lintas & $\mathrm{I}$ & 1 & $3,13 \%$ \\
\hline 5 & Memeras/mengancam & $\mathrm{I}$ & 1 & $3,13 \%$ \\
\hline \multicolumn{2}{|r|}{ Jumlah } & 32 & 32 & $100 \%$ \\
\hline
\end{tabular}

Berdasarkan tabel 5 di atas dapat diperoleh hasil deskripsi kasus subjek penelitian yang menunjukkan kasus perlindungan anak berjumlah 15 orang $(46,8 \%)$, kasus pencurian berjumlah 9 orang $(28,3 \%)$, kasus narotika berjumlah 6 orang $(18,75 \%)$, kasus lalu lintas berjumlah 1 orang $(3,13 \%)$ dan kasus memeras atau mengancam berjumlah 1orang $(3,113 \%)$.

Hasil analisis deskriptif data strategi regulasi emosi narapidana anak di LPKA Tj. Pati Payakumbuh, terangkum dalam Tabel 6 berikut ini:

Tabel 6

Dimensi Regulasi Emosi yang dialami Narapidana Anak

\begin{tabular}{|c|c|c|c|}
\hline \multirow{2}{*}{ No } & \multirow{2}{*}{ Subjek } & \multicolumn{2}{|c|}{ Dimensi } \\
\hline & & $\begin{array}{l}\text { Cognitive } \\
\text { reappraisal }\end{array}$ & $\begin{array}{l}\text { Expressive } \\
\text { suppresion }\end{array}$ \\
\hline 1 & A1 & $\sqrt{ }$ & - \\
\hline 2 & A2 & $\sqrt{ }$ & _- \\
\hline 3 & A3 & $\sqrt{ }$ & - \\
\hline 4 & A4 & $\sqrt{ }$ & - \\
\hline 5 & A5 & $\sqrt{ }$ & - \\
\hline 6 & A6 & $\sqrt{ }$ & $\sqrt{ }$ \\
\hline 7 & A7 & $\sqrt{ }$ & $\sqrt{ }$ \\
\hline 8 & A8 & $\sqrt{ }$ & - \\
\hline 9 & A9 & $\sqrt{ }$ & - \\
\hline 10 & A10 & $\sqrt{ }$ & $\sqrt{ }$ \\
\hline 11 & A11 & $\sqrt{ }$ & $\sqrt{ }$ \\
\hline 12 & A12 & $\sqrt{ }$ & - \\
\hline 13 & A13 & $\sqrt{ }$ & - \\
\hline 14 & A14 & $\sqrt{ }$ & - \\
\hline 15 & A15 & $\sqrt{ }$ & - \\
\hline 16 & A16 & $\sqrt{ }$ & - \\
\hline 17 & A17 & $\sqrt{ }$ & $\sqrt{ }$ \\
\hline 18 & A18 & $\sqrt{ }$ & - \\
\hline 19 & A19 & $\sqrt{ }$ & - \\
\hline 20 & A20 & $\sqrt{ }$ & $\sqrt{ }$ \\
\hline
\end{tabular}




\begin{tabular}{|l|l|l|l|}
21 & A21 & $\sqrt{ }$ & - \\
\hline 22 & A22 & $\sqrt{ }$ & - \\
\hline 23 & A23 & $\sqrt{ }$ & - \\
\hline 24 & A24 & $\sqrt{ }$ & - \\
\hline 25 & A25 & $\sqrt{ }$ & - \\
\hline 26 & A26 & $\sqrt{ }$ & - \\
\hline 27 & A27 & $\sqrt{ }$ & - \\
\hline 28 & A28 & $\sqrt{ }$ & - \\
\hline 29 & A29 & $\sqrt{ }$ & - \\
\hline 30 & A30 & $\sqrt{ }$ & - \\
\hline 31 & A31 & $\sqrt{ }$ & $\sqrt{ }$ \\
\hline 32 & A32 & $\sqrt{ }$ & - \\
\hline
\end{tabular}

Sebanyak 32 orang narapidana anak menggunakan strategi regulasi emosi cognitive reappraisal dalam permasalahan yang ada di LPKA dan sebanyak 7 narapidana anak menggunakan kedua strategi regulasi emosi yaitu cognitive reappraisal dan expressive suppresion.

\section{Pembahasan}

Berdasarkan hasil temuan penelitian yang telah dipaparkan pada bab sebelumnya terhadap subjek penelitian, diperoleh jawaban yang mengungkap tentang strategi regulasi emosi pada narapidana anak di LPKA Tanjung Pati, dapat diuraikan sebagai berikut:

\section{Secara umum}

Berdasarkan kategori regulasi emosi diperoleh gambaran sebanyak 3 orang mengalami regulasi emosi pada kategori tidak baik sebesar 9,37\%, 23 orang pada kategori cukup baik sebesar $71,87 \%$ dan 6 orang pada kategori sangat baik sebesar $18,75 \%$.

Berdasarkan kategori usia narapidana anak diperoleh hasil deskripsi usia subjek penelitian yang menunjukkan usia 14 tahun berjumlah 2 orang $(6,25 \%)$, usia 15 tahun berjumlah 2 orang $(6,25 \%)$, usia 16 tahun berjumlah 8 orang( $25 \%$ ), usia 17 tahun berjumlah 7 orang $(21,88 \%)$, usia 18 tahun berjumlah 11 orang $(34,38 \%)$,usia 19 tahun berjumlah 1 orang $(3,13 \%)$.

Berdasarkan kategori jenis kelamin, narapidana anak diperoleh hasil sebanyak 32 orang $(100 \%)$ anak didalam LPKA adalah laki-laki.

Berdasarkan kategori agama dapat diperoleh hasil deskripsi agama subjek penelitian yang menunjukkan beragama islam berjumlah 32 orang $(100 \%)$.

Berdasarkan kategori pendidikan narapidana anak yang menunjukkan pendidikan SD berjumlah 8 orang $(25 \%)$, SMP berjumlah 10 orang $(31,25 \%)$, SMA berjumlah 14 orang $(43,75 \%)$.

Berdasarkan kategori kasus narapidana anak menunjukkan. Yang terlibat dalam kasus perlindungan anak berjumlah 15 orang $(46,8 \%)$, kasus pencurian berjumlah 9 orang $(28,3 \%)$, kasus narkotika berjumlah 6 orang $(18,75 \%)$, kasus lalu lintas berjumlah 1 orang $(3,13 \%)$ dan kasus memeras atau mengancam berjumlah 1 orang $(3,113 \%)$.

Berdasarkan temuan peneliti di Lembaga Pembinaan Khusus Anak (LPKA) Klas II Tanjung Pati menunjukkan bahwa anak-anak yang berada didalam LPKA lebih banyak menggunakan Strategi Regulasi Emosi Cognitive Reappraisal. 
Hal ini di dukung dengan hasil wawancara yang dilakukan kepada subjek, didapatkan hasil bahwa sebagian besar dari subjek dapat menyalurkan emosinya dengan cukup baik.

\section{Secara Khusus}

\section{Dimensi Strategi Regulasi Emosi}

\section{1) Cognitive Reapraisal}

Berdasarkan hasil penelitian yang telah dilakukan terhadap narapidana anak di LPKA tanjung pati,diperoleh hasil bahwa diantara 32 orang subjek semuanya menggunakan strategiregulasi emosi cognitive reappraisal yaitu ketika mereka ingin melakukan tindakan mereka selalu mempertimbangkan dengan cara berfikiran positif ketika orang lain mengabaikan sapaan mereka, tidak berpikiran untuk membenci teman yang menjauhinya, berpikiran positif ketika orang lain memarahinya ketika berbuat kesalahan dan selalu introspeksi diri ketika teman menjauhinya serta berbicara positif ketika marah. Gross dan John (2003) menyatakan Cognitive Reappraisal adalah bentuk perubahan pemikiran mengenai situasi untuk mengurangi dampak emosional.Hal diatas sejalan dengan teori Eisenberg (dalam Hasanah, 2010) regulasi emosi adalah mencapai sesuatu melalui usaha mengatur perhatian meliputi mengubah gangguan dan memfokuskan perhatian dan menyadari situasi yang mengarah ke emosi dengan membangun pemikiran positif dengan baik melalui proses neuropsikologis.

\section{2) Expressive Suppresion}

Berdasarkan hasil penelitian yang telah dilakukan terhadap narapida anak di LPKA tanjung pati, diperoleh hasil bahwadiantara 32 subjek penelitian 7 orang menggunakan strategi regulasi emosi expressive suppression dengan cara subjek memilih menghancurkan barang-barang yang ada disekitarnya, tidur, melaksanakan ibadah seperti sholat dan mengaji ketika merasa marah atau tersinggung oleh lain serta lebih suka memendam kesedihannya sendiri dari pada menunjukkan kepada temannya yang lain. Shapper \& Gross (2012) menyatakan bentuk dari suppression terjadi melalui reaksi fisiologis seperti menggigit jari, relaksasi melalui pernafasan, berteriak, dan lain sebagainya.

\section{Kesimpulan}

Berdasarkan hasil analisis data yang telah diuraikan sebelumnya, maka dapat ditarik simpulan bahwa diperoleh gambaran sebanyak tiga orang mengalami regulasi emosi pada kategori tidak baik, dan sebanyak dua puluh tiga orang pada kategori cukup baik, dan enam orang pada kategori sangat baik.

Strategi Regulasi Emosi yang dilakukan oleh narapidana anak sebagian besar menggunakan Strategi Cognitive Reappraisal yaitu dengan cara ketika mereka ingin melakukan tindakan mereka selalu mempertimbangkan dengan cara berfikiran positif ketika orang lain mengabaikan sapaan mereka, tidak berpikiran untuk membenci teman yang menjauhinya, berpikiran positif ketika orang lain memarahinya ketika berbuat kesalahan dan selalu introspeksi diri ketika teman menjauhinya serta berbicara positif ketika. Serta strategi regulasi yang kedua yang dilakukan adalah expressive suppression yaitu dengan cara, melampiaskan emosinya terdahap orang lain atau barang yang ada disekitannya, tidur dan lebih suka memendam kesedihannya sendiri dari pada menunjukkan kepada temannya yang lain.

\section{Saran}

1. Bagi Sampel Penelitian

Disarankan kepada narapidana anak yang ada di Lembaga Pembinaan Khusus Anak Klas II di Tanjung Pati Payakumbuh agar tetap selalu berpikiran positif terhadap segala sesuatu 
yang terjadi dan selalu mendekatkan diri kepada Allah SWT maka akan menjadikan hati lebih tenang, ikhlas menerima, dan lebih sabar dalam menjalani kehidupan.

2. Bagi Lembaga Pembinaan Khusus Anak (LPKA) Klas II Tj. Pati

Disarankan kepada petugas LPKA agar lebih meningkatkan pemberian dukungan berupa arahan, nasehat dan bimbingan kepada narapidana anak agar mereka dapat mengelola dan mengatur emosi dengan lebih baik lagi agar narapidana anak mampu mengelola emosiemosi negatif yang dialaminya seperti perasaan sedih, marah kecewa, atau frustasi dengan baik agar ketenangan dan keharmonisan sosial terjaga didalam LPKA.

3. Bagi peneliti lainnya

Bagi peneliti lain, diharapkan hasil penelitian ini dapat dijadikan sebagai masukan, bahan informasi dan referensi dalam melakukan penelitian lebih lanjut dengan bidang yang sama. Dan bagi yang berminat mengadakan penelitian dengan topik yang sama, disarankan untuk memperhatikan faktor-faktor lain dalam regulasi emosi, yaitu Situation Selection, Situation Modification, Attention Deployment, Cognitive Change dan R espon Modulation.

\section{Referensi}

[1] Anggraini, Erlina. 2015. Strategi Regulasi Emosi dan Perilaku Koping Religius Narapidana Wanita Dalam Masa Pembinaan. Skripsi (diterbitkan). Semarang : Universitas Islam Negri Walisongo

[2] Azwar, Saifuddin. 2014. Metode Penelitian. Jakarta : Pustaka Pelajar

[3] Fajriani, Nice. 2008. Gambaran Penyesuaian Diri Anak Lapas Anak Pria Tengerang. Jurnal. Depok : Universitas Indonesia

[4] Gross, J. J. And John, O. P. 2003. Individual Differences In Two Emotion Regulation Proecesses : Implication For Affect, Relationships, and Well-Being. Journal Of Personality and Social Psychology, 85(2), 348-362

[5] Herdiansyah, Haris. 2014. Metodologi Penelitian Kualitatif. Jakarta : Salemba Humanika

[6] Mukhlis, Akhmad. 2011. Pengaruh Terapi Membatik Terhadap Depresi Pada Narapidana. Jurnal. Malang : Universitas Islam Negri Maulana Malik Ibrahim

[7] Putra, Rizki Yosandra. 2017. Burnout Pada Petugas Penjaga Palang Pintu PT. Kereta Api Indonesia Kota Padang. Skripsi (tidak diterbitkan). Padang : Universitas Putra Indonesia "YPTK"

[8] R, Festa Yumpi. 2016. Peran Orang Tua Pada Regulasi Emosi Anak Autis. Jurnal Vol 12, No. 1, April 2016

[9] Sugiyono. 2012. Metode Penelitian Kualitatif, Kuantitatif dan $R \&$ D. Bandung : Alfabeta

[10] Suryabrata, Sumadi. 2015. Metode Penelitian. Jakarta : PT. RajaGrafindo Persada

[11] Syahadat, Yustisi Maharani. 2013. Pelatihan Regulasi Emosi Untuk Menurunkan Perilaku Agresif Pada Anak.Jurnal Humanitas, Vol. X No. 1 Januari 2013 